REVISTA DE DERECHO UNED, núm. 6, 2010

\title{
CALIDAD Y DISTINTIVOS TURÍSTICOS EN LA LEY DE TURISMO DE GALICIA
}

\author{
M $^{\mathrm{a}}$ DEL Mar Gómez Lozano \\ Profesor Contratado Doctor. \\ Área de Derecho Mercantil. Universidad de Almería
}

En el marco de la defensa de un turismo de calidad, la Ley 14/2008, de 3 de diciembre, de Turismo de Galicia (DOG núm. 246, de 19 de diciembre de 2008 y BOE núm. 64, de 16 de marzo de 2009), ha regulado los distintivos que se van a utilizar para promocionar Galicia como destino turístico ${ }^{1}$.

Desde que en 1964 se creó a nivel estatal el Registro de Denominaciones Geoturísticas muy pocas Comunidades Autónomas habían incorporado a su normativa turística una regulación de este carácter. En el caso de Galicia, la normativa anterior (Ley 9/1997, de 21 de agosto, de ordenación y promoción del turismo en Galicia, que ha sido derogada por la Disposición Derogatoria Única de la Ley 14/2008), se refería únicamente a las denominaciones geoturísticas en el artículo 6.2, letra d), al calificar como competencia de la Comunidad Autónoma «la creación y definición de denominaciones geoturísticas dentro de su ámbito territorial».

La Ley 14/2008, de 3 de diciembre, de Turismo de Galicia distingue actualmente en el Título IV, dedicado a regular la ordenación de la actividad turística, dos tipos de distintivos de promoción de los re-

${ }^{1}$ Las disposiciones que se citan en esta noticia no se han visto afectadas por la reforma de la ley operada en virtud del artículo 21 de la Ley 1/2010, de 11 de febrero, de modificación de diversas leyes de Galicia para su adaptación a la Directiva 2006/123/CE, del Parlamento Europeo y del Consejo, de 12 de diciembre de 2006, relativa a los servicios en el mercado interior (DOG núm. 36, de 23 de febrero de 2010 y BOE núm. 86 de 9 de abril de 2010). 
cursos turísticos gallegos: las que denomina «marcas turísticas» y las «denominaciones geoturísticas». Estos distintivos de promoción deben diferenciarse de otros que se utilizan también en el sector turístico. En primer lugar, de los que podrían denominarse «distintivos de empresas turísticas», que serían aquellos que los diferentes operadores turísticos utilizan para identificar los productos y servicios que ofrecen en el mercado. Y en segundo lugar, deben diferenciarse también de los distintivos que simplemente constituyen «medios de señalización turística» y que entre los elementos identificadores incluyen la imagen visual corporativa (vid. art. 13 del Decreto 138/2008, de 22 de mayo, de señalización turística de Galicia).

La marca turística "Galicia» como estrategia de promoción, servirá para impulsar la proyección interior y exterior de Galicia como marca turística global y de calidad que integra y respeta las demás marcas turísticas gallegas (art. 17.1). De este precepto puede deducirse que se ha querido diseñar un amplio grupo de marcas turísticas. Unas de carácter específico para identificar individualmente los recursos turísticos concretos de la Comunidad y otra de carácter global que servirá para promocionar Galicia de forma integrada. Desde el punto de vista del marketing, estas estrategias de promoción entrarían dentro de las denominadas «marcas paraguas».

Las distintas marcas turísticas de carácter específico podrían tener por objeto los distintos segmentos de la oferta turística, como el turismo rural, el turismo termal o el gastronómico [vid. art. 54.1, letra b)]. En este sentido, puede indicarse a título de ejemplo, que en el Principado de Asturias, el Decreto 69/1994, de 1 de septiembre aprueba la utilización de la marca "Casonas Asturianas» para diferenciar la oferta turística alojativa y la Resolución de 14 de octubre de 2002 aprobó el Reglamento de Uso de la marca «Mesas de Asturias. Excelencia Gastronómica», que sirve para distinguir aquellos establecimientos de restauración del Principado que reúnan las condiciones fijadas en el Reglamento y cuya utilización fue objeto del Decreto 75/2002, de 6 de junio.

Será la administración turística la encargada de promocionar la imagen turística de Galicia en los mercados adecuados, con la colaboración de las entidades municipales y supramunicipales debiendo siempre reflejarse la pluralidad de la oferta turística del país (art. 17.2). En el ejercicio de estas competencias, y en especial en lo que respecta a las funciones de coordinación de las acciones de promoción, la Administración de la Comunidad Autónoma podrá declarar obligatoria la inclusión del nombre «Galicia» y de los logotipos y le- 
mas que se establezcan en las campañas de promoción impulsadas por las entidades locales gallegas (art. 17.3). Debe observarse que esta posibilidad, que podría ser concretada en el desarrollo reglamentario de la Ley, afecta no sólo a los entes públicos, sino también a las empresas y asociaciones turísticas que desarrollen campañas de promoción utilizando fondos públicos (art. 17.4).

También respecto a estas marcas turísticas de calidad, el nuevo Consejo Regulador del Turismo tendrá las competencias para elaborar una propuesta de Reglamento que deberá ser aprobado por Decreto de la Xunta en el que se determinen los requisitos y el procedimiento para la obtención de las marcas turísticas de calidad (art. 18). Al Consejo regulador también corresponderá la revisión periódica de los criterios para la obtención de dichas marcas. Lo dispuesto en este precepto hace pensar que la marca turística global "Galicia» adoptará la forma de una marca de carácter colectivo (marca colectiva o marca de garantía según las categorías de la Ley 17/2001, de 7 de diciembre, de Marcas).

La Ley establece también una concreta distribución competencial en torno a la promoción de marcas turísticas. Así, entre las competencias atribuidas a la administración de la Xunta de Galicia figura la de la promoción y protección de la imagen de Galicia como marca turística [art. 4.1, letra c)] y entre las competencias de las entidades locales supramunicipales aparece incluida la promoción de los recursos y de las marcas turísticas de su ámbito territorial en coordinación con todos los entes legales afectados [art. 6.1, letra a)]. Por otra parte, el Consejo Regulador del Turismo de Galicia, tiene entre sus atribuciones, la de favorecer el desarrollo de una oferta turística gallega de calidad mediante la elaboración y reglamentación de marcas turísticas de calidad [art. 7.2, letra b)], correspondiendo además a la propia Red Gallega de Oficinas de Turismo el fomento de la imagen de Galicia como marca turística (art. 8.2).

En relación con el otro grupo de distintivos de promoción turísti$\mathrm{ca}$, las denominaciones geoturísticas, hay que señalar que tienen una regulación específica en el artículo 19 de la Ley. A imagen del registro creado en 1964 y según fue imitada esta iniciativa en otras Comunidades Autónomas (Murcia y Castilla y León), se diseña un nuevo régimen jurídico administrativo para estos distintivos que tienen ya un indudable carácter autonómico en virtud de las competencias constitucionales asumidas por las Comunidades Autónomas en materia de promoción turística en su ámbito territorial. En este caso, la Xunta, una vez oídos los Concejos que puedan estar afectados, podrá 
definir, crear y otorgar denominaciones geoturísticas a itinerarios turísticos o rurales, a áreas concretas (como podrían ser las costas) y a determinadas localidades, concejos o comarcas que presenten especiales características que así lo aconsejen para la promoción y ordenación de la actividad turística (art. 19.1). Cabe destacar la importancia que tienen en esta Comunidad Autónoma, como itinerarios turísticos internacionalmente conocidos, el «Camino de Santiago» o la «Vía de la Plata», aunque en su promoción se ven implicadas también otras Comunidades Autónomas. En este marco, debe indicarse que la Xunta de Galicia ha incluido entre las actuaciones promocionales «la concertación de acciones conjuntas de promoción turística con otras Comunidades Autónomas, con la Administración General de Estado y con las administraciones de otros estados, en especial con la República Portuguesa en el marco de la eurorregión Galicia-Norte de Portugal» [art. 52.2, letra d)].

El uso de las denominaciones geoturísticas se atribuye en la Ley a entidades públicas y privadas para la promoción turística de las zonas o de los itinerarios a los que se refieran (art. 19.2). Pero no debe deducirse de ello que sólo los operadores calificados en esta Ley como empresas turísticas son los únicos legitimados para utilizar estos distintivos. Piénsese, por ejemplo, en los Consejos Reguladores de las denominaciones de origen, que podrían también realizar promoción turística en el marco de su actividad agroalimentaria o en los titulares de marcas de garantía de productos agroalimentarios, que podrían suscribir convenios para realizar promoción turística a través de estas marcas (ver, por ejemplo, el artículo 8.4 del Reglamento de uso de la marca "C'alial» creada por el Gobierno de Aragón, que establece como facultades del titular de la marca que «a los efectos de promoción, el titular podrá concluir convenios o acuerdos de colaboración con otros entes públicos para, en particular, fomentar valores turísticos» que figura como Anexo I a la Orden de 25 de julio de 2007, del Departamento de Agricultura y Alimentación, por la que se establece el sistema de gestión, uso y control de la marca "C'alial» en alimentos de calidad diferenciada).

El régimen de las denominaciones geoturísticas de la Ley 14/2008 se completa con la referencia a la existencia de un registro en el que inscribirlas. Así, el apartado 3 del artículo 19 establece que en la Consejería competente en materia de turismo, existirá un «Registro de denominaciones geoturísticas de Galicia» de naturaleza administrativa y de carácter público en la que se inscribirán, en los términos que reglamentariamente se establezcan, las denominaciones geoturísticas que otorgue la Xunta de Galicia. Habrá que incluir en este re- 
gistro las denominaciones gallegas que ya figuraban inscritas en el Registro creado en 1964: "Rías Bajas Gallegas» (Orden de 10 de diciembre de 1964); «La Toja, Isla de Ensueño» (Orden de 10 de febrero de 1966); "El Grove, Paraíso del marisco» (Orden de 6 de febrero de 1967) y «Perla de Arosa» (Orden de 30 de mayo de 1970).

$\mathrm{Al}$ tratarse de una norma de carácter administrativo, debe destacarse que tipifica como infracción grave el uso de marcas o denominaciones geoturísticas que no correspondan o que incumplan las condiciones reglamentariamente establecidas [art. 70, letra g)]. 
